
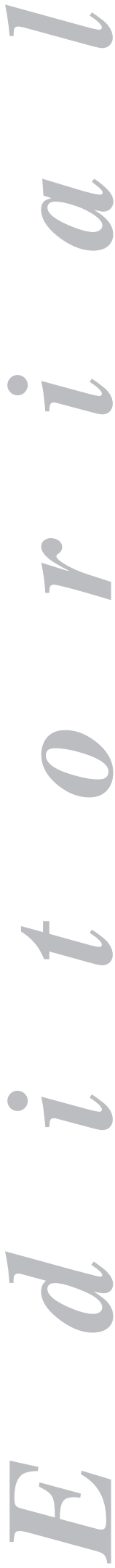

\section{Selective colorectal cancer screening in average-risk populations}

The great significance of colorectal cancer (CRC) and of understanding its etiopathogenesis and natural history allows that programs be implemented to prevent its development (primary prevention), to detect it in early or pretumoral stages (secondary prevention or screening), or to reduce its impact on patient prognosis (tertiary prevention or monitoring) (1). Here we shall not deal with primary or tertiary prevention; we shall focus on secondary prevention - CRC screening.

Screening literally is "the act of passing a substance through a screen or sieve to separate smaller from greater parts"; in other words, to select rigorously. Screening attempts to identify a previously non-diagnosed health issue using the appropriate procedures to recognize positive subjects (those with the health issue) from negative individuals (those without the health issue). When applied to a whole population it is designated "mass screening", and "selective screening" when used for groups at risk. "Average or moderate risk" refers to an absence of established high-risk factors -a family history of CRC or multiple polyposis, predisposing patient factors such as acromegaly, nephrourological disorders, breast or endometrial cancer- except for age older than 50. Screening should not be mistaken for monitoring, which is the follow-up of patients having undergone a procedure to excise a colonic adenomatous polyp or CRC, or of subjects with CIBD, and thus represents a type of tertiary prevention.

Screening is applied when three criteria are met: a) the disease has a detectable preclinical stage or precursor lesion; $b$ ) once revealed a preventive procedure is feasible; and c) taking this action will result in a better outcome than otherwise would be the case. Should these three criteria remain unmet, screening will not bring about better outcomes than abstention (2). Therefore CRC -which has a high incidence, prevalence, and mortality, with mean five-year survival at $50 \%$ and a relapse (local or distant) rate of 30-50\% after 2-3 years following curative-intent surgery- is ideal for screening since deaths are cost-effectively and significantly decreased by removing precursor lesions or diagnosing early-stage CRC.

\section{Advanced adenoma as the primary target of CRC screening}

The adenoma $\rightarrow$ carcinoma sequence as a development pattern for CRC has been known since the studies by Lockart-Mummery and Dukes were reported in 1920; Morson described it in depth as the "polyp-cancer sequence" in 1977, and both Stryker in 1986 and Winawer in 1993 finally demonstrated its presence. The adenoma $\rightarrow$ CRC conversion rate is estimated around 0,25\%/year; the natural history of this sequence entails a time lapse of 10-20 years, and provides an opportunity 
for intervention on tumor precursor lesions. Not only CRC-related deaths but also $\mathrm{CRC}$ development and both diagnosis- and therapy-derived costs are reduced in this way.

Adenomas have a global prevalence of 30-50\% according to necropsy studies in western countries, superior to that found in diagnostic colonoscopies (15-29\%), with $75 \%$ being distal lesions; their frequency is higher in males, and increases with age (3). Multiple adenomas are associated with a high risk of progression to advanced adenomas (AAs), which are a histological marker for CRC risk. AA include some of the following characteristics: a) size $>1 \mathrm{~cm}$; b) $>25 \%$ of tissue with villous adenoma features; c) serrated adenomas; and d) high-grade dysplasia. This definition includes pediculated and flat adenomas, but also considers the number of resected adenomas and their characteristics: 2 or fewer adenomas, all $<1 \mathrm{~cm}$ and no AA: risk similar to that of the general population; for 3 or more adenomas, $>1 \mathrm{~cm}$ and AA: group at high risk (4). This approach using screening programs provides better adjusted outcomes for measuring the preventive interventionist effect of endoscopic polypectomy.

We shall focus now on the screening of asymptomatic individuals with average risk, that is, of subjects whose one risk factor is age $>50$ years, highlighting the fact no optimal screening strategy has been established thus far, which depends on the selected test and the setting where it is implemented.

\section{Screening strategy types in average-risk subjects}

CRC screening guidelines have been published since 1997 for average-risk subjects based on available literature reviews or recommendations by scientific societies (5). They are generally consistent with screening guidelines for colonic adenomatous polyps (6). Strategies include: a) fecal occult blood testing (FOBT) every 1-2 years; b) sigmoidoscopy every 5 years; c) FOBT and sigmoidoscopy every 5 years; d) double-contrast enema every 5 years; and e) colonoscopy every 10 years $(5,7,8)$.

Evidence on the efficacy of each strategy varies. FOBT alone has proven effective in prospective studies, followed by sigmoidoscopy or colonoscopy for all positive patients. Mortality reductions vary depending on whether FOBT is performed biannually (15-18\%) or annually (22-33\%) (7). Stand-alone FOBT is unsatisfactory for $\mathrm{CRC}$ prevention screening since the positivity rate for colonic adenomas is low, even for AA; hence the American Cancer Society does not recommend FOBT as only screening test, and also advices on annual rather than biannual repeats (8). WGO/OMG combines screening recommendations per risk level, with resource availability at implementation points: from level 1 (greater resources) to level 6 (minimal resources available), which makes recommendations applicable worldwide (9). This editorial will refer to resource level 1 , the one available in Western Europe and industrialized countries.

A specific screening is available for each risk group: a) average risk: individuals $>50$ years with no other predisposing factors; and b) high risk: individuals who have first-degree relatives with sporadic CRC or hereditary non-polyposis colorectal cancer (HNPCC or Lynch syndromes). In this condition and in familial adenomatous polyposis (FAP) a presymptomatic diagnosis may be reached by analyzing DNA repair gene mutations (MSH2, MSH6 and MLH1) or the presence of APC gene, respectively $(4,6)$. 


\section{Using screening for populations at intermediate (moderate) risk}

Recommendations are identical for the screening of adenomatous polyps and $\mathrm{CRC}$, and target the asymptomatic population with no additional risk factors from 50 to 75 years of age; its extension to $80-85$ years of age is optional $(5,8)$. The screening method depends on subject acceptability and resource availability; let us remember that FOBT has a sensitivity of $25 \%$ for adenomatous polyps $<1 \mathrm{~cm}$, and of $40-50 \%$ for polyps $>1 \mathrm{~cm}$, whereas for CRC it approaches $75 \%$. When FOBT is performed with immunological methods rather than guaiac sensitivity increases and both participation and compliance rise since no dietary restrictions apply, but specificity decreases. Other advantages include: avoidance of direct reading subjectivity because of automation, and a high number of measurements in a short time (10).

While annual FOBT, flexible sigmoidoscopy every 5 years, and complete colonoscopy every 10 years are effective screening tools on their own right, findings support advocacy for combining FOBT with any of the two endoscopic techniques, which also allow removal of any adenomatous polyps present. Thus the sensitivity, specificity, and acceptability limitations of each test are corrected. Double-contrast enema (DCE) was recommended based on a literature review $(2,5)$, but no studies are available on the effectiveness of CRC screening with DCE, which is known to detect only $50 \%$ of polyps $>1 \mathrm{~cm}$ and fewer than $25 \%$ of smaller lesions $(5,11)$. ACG does not support it as a primary screening strategy for individuals with average risk (12), nor the Oncoguía de la Comunidad Valenciana (4) or Guía de práctica clínica española de la prevención del CCR in its 2009 edition (13). Virtual colonoscopy or colonic tomography is an as yet non-recommended screening test $(4,5,13)$, even though its sensitivity for AA is $92 \%$ (6).

Wagner et al. were first to examine the strategies recommended by the Agency for Health Care Policy and Research (AHCPR) in average-risk subjects (14). Costbenefit ratios were analyzed for 16 screening strategies -some of them on their own: a) annual FOBT; b) sigmoidoscopy every 3, 5, or 10 years; c) DCE every 3, 5, or 10 years; d) complete colonoscopy every 3,5 , or 10 years; some of them in combination; e) annual FOBT + sigmoidoscopy every 3, 5, and 10 years; and f) annual FOBT + DCE every 3, 5, and 10 years. It was assumed that screening ceased at 85 years of age. Costs were included for tests, adenoma excision, and complications. Their model estimated change in "dollars per life-year gained", and this was comparable to that of other population screening strategies such as mammography. All CRC screening strategies considered had a positive cost-benefit ratio; any AHCPR strategy was cost-effective when compared to no strategy at all.

Khandker et al. (15), in an average-risk population and from 50 through 85 years of age, analyzed the cost-effectiveness of CRC screening. Their conclusions where similar, but on reducing compliance down to $25 \%$ less sensitive strategies such as FOBT proved most cost-ineffective. Flexible sigmoidoscopy every 5 years was among the best, but when colonoscopy costs were reduced the latter study proved most cost-effective since AA detection using colonoscopic screenings is superior. Also, when a proximal AA is found with sigmoidoscopy a complete colonoscopic study becomes mandatory, as the risk for synchronic CRCs or AAs duplicates $(5,6)$.

The Council of the European Union recommends that CRC screening be offered to both males and females at 50-75 years of age. A number of pilot studies are now ongoing in Spain since 1996: in Navarre, Guadalajara, Madrid, Barcelona, Canary Islands, Seville, Segovia, Albacete, Valencia, and Murcia; they all use FOBT for screening (with either guaiac or immunochemistry) followed by endoscopy for pos- 
itive cases. Some studies had to be discontinued because of low participation rates regarding FOBT, which was particularly pronounced among the elderly and selected ethnic groups (africans, gypsies, maghrebians), as well as in low-income individuals.

Other authors suggest colonoscopy for diagnosis confirmation (16); in this paper populations at 40-49 years of age were compared to those at 50-59 years; the incidence of adenomas was found to be similar in both (14 and 16\%, respectively), but AA rates were twice as big in the older-age group (3.7 vs. 2\%). In the latter group 1 $\mathrm{CRC}$ was found after 352 colonoscopies, whereas none was found during the 553 procedures performed in the younger population. An age gradient (similar for both genders) for the adenoma $\rightarrow$ AA transition was shown by Brenner et al. (17), who revealed that from 55-59 to 75-79 years of age the incidence of AA increases from 3.4 to $6.5 \%$ (91\%) in females, and from 6.2 to $9.7 \%$ (56\%) in males, with no further increases after age 80 .

Using colonoscopy for confirmation requires an optimal performance (thorough colon cleansing, expert endoscopist, support anesthesiologist, cecal intubation in $100 \%$, slow colonoscope withdrawal, use of visualization maximizing techniques such as chromoendoscopy for flat adenomas or magnification endoscopy), and attention to potential complications (15). An expert performer is a key factor -a Canadian research found that a previous (within three months) colonoscopy by an internist, family physician, or gastroenterologist at a private practice yielded an incidence of overlooked CRCs oscillating between 2.1 and $-2.3 \%$ in the left colon, and of $5.9 \%$ in the right colon and cecum (18).

Regarding the above is the paper included in this issue of REED by Dr. M. Navarro et al. (19), which discusses population selection strategies for 50-69-yearold subjects at average risk of CRC in L'Hospitalet, a town within Barcelona metropolitan area, and does not obviate family histories of CRC (5\% had such history). Two screening rounds using FOBT-guaiac were made (interval of two years), and all subjects ( $40 \%$ participated in both rounds) with positive samples (2.7\% of participants) were offered a colonoscopy under sedation, which $89 \%$ accepted; 27 nonneoplastic polyps (6.1\%), 150 adenomas (33.9\%) of which 121 were AAs (27.4\%); and $36 \mathrm{CRCs}(8.1 \%)$ were found. Male gender and a positive family history for CRC were independent diagnostic factors for AA, with an OR of 2.5 and 1.98, respectively; in contrast, no association was found between previous rectorrhage and endoscopic findings, since $42 \%$ of those reporting the former had no significant colonoscopic findings. This paper complements that reported by this same group in this journal last year (20), where, in the same population, most lesions (37.2\%) were found in the distal colon.

\title{
M. Bixquert-Jiménez
}

\author{
Department of Medicine. School of Medicine of Valencia. Service of Digestive
} Diseases. Hospital Arnau de Vilanova. Valencia, Spain

\section{REFERENCES}

1. Bessa X, Castells A. Cáncer colorrectal. En: Ponce J, editor. Tratamiento de las enfermedades gastroenterológicas. $2^{\mathrm{a}}$ ed. Barcelona: SCM; 2006. p. 327-37. 
2. Winawer SJ, Fletcher RH, Millar L, et al. Colorectal cancer screening: clinical guidelines and rationale. Gastroenterology 1997; 112: 594-642.

3. O'Brien MJ, Winawer SJ, Zauber AG, et al. The National Polyp Study. Patient and polyp characteristics associated with high-grade dysplasia in colorectal adenomas. Gastroenterology 1990; 98: 371-9.

4. Aparicio J, Canelles P, Cuevas D, et al. Oncoguia del Cáncer Colorrectal de la Comunidad valenciana. Generalitat. Conselleria de Sanitat; 2007.

5. Bresalier RS. Neoplasias malignas del intestino grueso. En: Sleisenger \& Fordtran. Enfermedades digestivas y hepáticas. $8^{a}$ ed. en español. Madrid: Elsevier-Saunders; 2008. p. 2759-810.

6. Itzkowitz SH, Rochester J. Pólipos colónicos y síndromes de poliposis. En: Sleisenger \& Fordtran. Enfermedades digestivas y hepáticas. $8^{\mathrm{a}}$ ed. en español. Madrid: Elsevier-Saunders; 2008. p. 2713-58.

7. Hardcastle JD, Chamberlain JO, Robinson MH, et al. Randomized control trial of faecal-occult blood screening for colorectal cancer. Lancet 1996; 346: 1472-7.

8. Byers T, Levin B, Rothenberger D. American cancer Society guidelines for screening and surveillance for early detection of colorectal polyps and cancer. ACS Detection and Treatment Advisory Group on Colorectal Cancer. Cancer J Clin 1997; 47: 154-60.

9. Winawer SJ, Classen M, Lambert R, et al. WGO/IDCA. Tamizaje del cáncer colorrectal. Organización Mundial de Gastroenterología (en español); 2007.

10. Quintero E. ¿Test químico o test inmunológico para la detección de sangre oculta en heces en el cribado del cáncer colorrectal? Gastroenterol Hepatol 2009; 32: 565-76.

11. Schrock TR. Colonoscopy versus barium enema in the diagnosis of colorectal cancer and polyps. Gastrointest Endosc Clin N A 1993; 3: 585-610.

12. Rex DK, Johnson DA, Lieberman DA, et al. Colorectal cancer prevention 2000: screening recommendations of the American College of Gastroenterology. Am J Gastroenterol 2000; 95: 868-77.

13. Guía de práctica clínica de prevención del cáncer colorrectal. Actualización 2009. AEG, semFyC y Centro Cochrane Iberoamericano. Barcelona: Elsevier; 2009.

14. Wagner JL, Tunis S, Brown M, et al. The cost-effectiveness of colorectal cancer screening in average-risk adults, en Young G, Levin B, Rozen A (eds), Prevention and early detection of colorectal cancer. Londres: WB Saunders; 1996. p. 321-56.

15. Khandker RK, Dulski JD, Kilkpatrick JB, et al. A decision model and cost-effectiveness analysis of colorectal cancer screening and surveillance guidelines for average-risk adults. Int J Tech Assess Health Care 2000; 16: 799-810.

16. Rundle AG, Lebwohl B, Vogel R, et al. Colonoscopic screening in average-risk individuals ages 40 to 49 vs 50 to 59 years. Gastroenterology 2008; 134: 1311-5.

17. Brenner H, Hoffmeister M, Stegmaier Ch, et al. Risk of progression of advanced adenomas to colorectal cancer by age and sex: estimates based on 840149 screening colonoscopies. Gut 2007; 56: 1585-9.

18. Bressler B, Paszat LF, Chen Z, et al. Rates of new or missed colorectal cancers after colonoscopy and their risk factors: a population-based analysis. Gastroenterology 2007; 132: 96-102.

19. Navarro M, Binefa G, Blanco I, et al. Colorectal cancer screening: strategies to select populations with moderate risk for disease. Rev Esp Enferm Dig 2009; 101: 855-60

20. Navarro M, Peris M, Binefa G, Nogueira JM, Miquel JM, Espinás JA, et al.; and the Catalan Colorectal Cancer Screening Pilot Programme Group. Colonoscopic findings from a pilot screening study for colorectal cancer in Catalonia. Rev Esp Enferm Dig 2008; 100: 343-8. 